\title{
A MODERNIZAÇÃO DA AGRICULTURA NO BRASIL: TRANSIÇÕES AGRÍCOLAS E AUTOGESTÃO
}

The modernization of agriculture in Brazil: agricultural transfers and selfmanagement

La modernización de la agricultura en Brasil: transferencias agrícolas y autogestión

\section{Arthur Saldanha do Santos}

${ }^{1}$ Doutorando em Sociologia na Universidade Federal do Rio Grande do Sul - UFRGS,

Porto Alegre, Brasil.

*Correspondência: Programa de Pós-Graduação em Sociologia, Instituto de Filosofia e Ciências Humanas, Bairro Agronomia, Porto Alegre, Rio Grande do Sul, Brasil. CEP:91501-970. E-mail arthur-ufvjm@hotmail.com.

\section{RESUMO}

Ao partir da problemática da condição alimentar na atualidade e suas configurações nos processos de produção no campo, entende-se que a modernização da agricultura funcionou como um divisor de águas no mundo, ao proporcionar o levantamento de críticas profundas e de dimensões diversificadas. Dentro destas condições, a problemática deste trabalho está centrada em verificar como as performances apresentadas pela autogestão da produção agrícola se afirmam no contexto pós modernização agrícola. O objetivo deste trabalho é compreender as implicações do processo de transformação da agricultura no Brasil, para os empreendimentos familiares de produção no campo. O trabalho proposto parte de uma investigação teórico-conceitual sobre o processo de modernização da agricultura no Brasil. A modernização no campo contribuiu para a redefinição dos processos agroalimentares, sendo base para o crescimento de críticas sobre a qualidade da produção, quantidade e as implicações negativas para o meio ambiente. As transições agrícolas observadas na agroecologia, por exemplo, reforçam a importância dessas críticas no sistema agroalimentar, bem como propõem a autogestão como alternativa para essa transição produtiva de forma justa entre os produtores e consumidores.

Palavras-chave: Agricultura; Autogestão; Modernização.

\begin{abstract}
Starting from the problem of the food condition nowadays and its configurations in the production processes in the field, it is understood that the modernization of agriculture has acted as a watershed in the world, by providing the survey of deep criticisms and diversified dimensions. Within these conditions, the problem of this work is centered on verifying how the performances presented by the self-management of agricultural production are affirmed in the context of post-agricultural modernization. The objective of this work is to understand the implications of the agricultural transformation process in Brazil, for family production enterprises in the field. The proposed work is part of a theoretical-conceptual investigation on the modernization process of agriculture in Brazil. Modernization in the field has contributed to the redefinition of agri-food processes, being the basis for growing criticism about the quality of production, quantity, and the negative implications for the environment. The agricultural transitions observed in agroecology, for example, reinforce the importance of these criticisms in the agri-food system, as well as proposing self-management as an alternative for this productive transition in a fair way among producers and consumers.
\end{abstract}

Keywords: Agriculture; Self-management; Modernization. 


\section{RESUMEN}

Partiendo del problema de la condición de los alimentos hoy en día y sus configuraciones en los procesos de producción en el campo, se entiende que la modernización de la agricultura ha actuado como un hito en el mundo, al proporcionar el estudio de críticas profundas y dimensiones diversificadas. Dentro de estas condiciones, el problema de este trabajo se centra en verificar cómo se afirman los rendimientos presentados por la autogestión de la producción agrícola en el contexto de la modernización "pos-agrícola". El objetivo de este trabajo es comprender las implicaciones del proceso de transformación agrícola en Brasil, para las empresas de producción familiar en el campo. El trabajo propuesto es parte de una investigación teórico-conceptual sobre el proceso de modernización de la agricultura en Brasil. La modernización en el campo ha contribuido a la redefinición de los procesos agroalimentarios, siendo la base para el aumento de las críticas sobre la calidad de la producción, la cantidad y las implicaciones negativas para el medio ambiente. Las transiciones agrícolas observadas en agroecología, por ejemplo, refuerzan la importancia de estas críticas en el sistema agroalimentario, además de proponer la autogestión como una alternativa para esta transición productiva de manera justa entre los productores y consumidores.

Descriptores: Agricultura; Autogestión; modernización.

\section{INTRODUÇÃO}

A trajetória da agricultura brasileira é consideravelmente discutida nas diversas áreas de estudo sobre o tema, sendo, portanto, necessário recorrer apenas aos traços mais específicos que consigam sustentar o cenário do surgimento da perspectiva sustentável na produção agrícola do país.

A Revolução Verde entendida como um processo de reconfiguração do campo, possibilitou a articulação de maneiras diferenciadas de compreensão da capacidade de utilização da natureza pela população, em atendimento às necessidades de consumo em massa. O desenvolvimento sustentável surge como fruto de mobilizações em níveis globais contrárias às dinâmicas produtivas predatórias, centrado na integração das dimensões social, econômico e ecológico nos diferentes espaços produtivos.

As transformações na agricultura redefiniram os modos de produção e contribuíram para o surgimento das reflexões críticas sobre a produção agroalimentar. Passa a ser central, portanto, a qualidade do alimento, quantidade e suas implicações para o meio ambiente. As transições agrícolas observadas na agroecologia, por exemplo, reforçam a importância dessas críticas no sistema agroalimentar, buscando uma transição produtiva de forma justa entre os produtores e consumidores.

\section{O PROCESSO DE MODERNIZAÇÃO NA AGRICULTURA BRASILEIRA}

A modernização enquanto um conceito adotado pelas Ciências Sociais, refere-se às mudanças experimentadas pela sociedade com a emergência da industrialização e urbanização iniciadas nas cidades. É a condição que permite a alteração das estruturas sociais, econômicas, políticas e culturais de uma sociedade. Na agricultura, a modernização representou a transformação da base técnica da produção, especialmente após a Segunda Guerra Mundial, com as intensas alterações da produção no campo ao utilizar inovações tecnológicas, visando melhorias no processo produtivo (GRAZIANO DA SILVA, 1982; 1996).

Ao tomar 'emprestado' algumas análises desenvolvidas na história sobre o processo de modernização da agricultura brasileira, percebe-se que no início da década de 1950, o Brasil já contava com interesses de modernização agrícola por parte dos incentivos governamentais. O papel desempenhado pelo Ministério da Agricultura no decorrer da Primeira 
República e Era Vargas (1910 - 1945) foi essencial ao viabilizar condições produtivas para grupos sociais com interesses favoráveis ao poder político vigente. Foram estimuladas a diversificação da produção direcionada para o mercado interno, os investimentos em pesquisas agrícolas na busca de alternativas produtivas (variedade e qualidade da produção), o estímulo à adoção de máquinas, insumos e adubos. $\mathrm{O}$ Ministério configurou-se em um importante mecanismos de conversão da produção agrícola em caráter industrial, alinhando os interesses da sociedade civil e da sociedade política no desenvolvimento da agricultura no Brasil (MENDONÇA, 2013).

A partir da análise da tese de atuação do Governo Vargas em reorganizar a vida rural no Brasil (1930-1945), Welch (2016) apresentou em seu trabalho algumas reflexões que valem de apontamentos para a análise da situação agrária do país antes dos anos 1950. Para o autor, esta organização orientada por estudos, leis, ideias e instituições para o campo, era justificada pela necessidade de transformar a sociedade rural para os moldes da moderna sociedade industrial. Como resultado dessa organização, foram criados mais de 8 mil sindicatos de trabalhadores rurais e foi observado um notável crescimento do agronegócio.

Tais modificações foram percebidas como uma atenção especial à população do campo, que até então era 'esquecida'. Neste processo, houve a integração "dos sindicatos rurais e patrões rurais" à "paisagem política e administrativa da sociedade brasileira", com o lema de cidadania e direitos sociais no campo. O período Vargas ficou conhecido quando se trata da questão agrária, como o período de

\footnotetext{
1 Independentemente da posição do autor (NAVARRO, 2001), por desenvolvimento, entende-se neste presente estudo ainda que de modo suscinto e carente de formulações complementares, o processo que possibilita a vivência das pessoas respeitando as suas escolhas. Mais do que isso, é um processo que presume mudanças, sejam elas para o
}

fortalecimento do capitalismo agrário, com "uma série de estudos, ideias, leis e instituições para a organização da vida rural que se mostrou parte permanente de seu legado" (WELCH, 2016, p. 101).

Ao analisar as possibilidades e limites do desenvolvimento rural no Brasil, Zander Navarro (2001) destacou em seu trabalho que o processo de modernização agrícola no Brasil desde seu início foi associado à perspectiva de desenvolvimento ${ }^{1}$, dividido em pelo menos dois períodos singulares entre os anos de 1950 e 2000, que se fundamentou a partir de interesses e debates políticos sobre o avanço econômico no país. Disputas sociais foram travadas em torno deste tema, uma vez que tal mudança presumia benefícios para determinados grupos sociais, enquanto outros tantos se tornariam marginalizados dessa possibilidade.

O primeiro período de desenvolvimento para o campo no Brasil pode ser compreendido do ano de 1950 ao final de 1970. Período este, marcado pelos resultados globais tanto da Guerra Fria quanto da Segunda Guerra Mundial, sinalizando a polarização do mundo em dois modelos antagônicos de crescimento econômico - socialismo e capitalismo. Este contexto é representado também, pelas profundas mudanças em termos de organização social, política, econômica, de modos de vida e de comportamentos sociais. Conforme salienta Navarro (2001), tais modificações estavam baseadas na possibilidade do desenvolvimento se concretizar como uma solução para melhorar a qualidade de vida das pessoas.

Já para Graziano da Silva (1999, p. 89), a industrialização do espaço rural brasileiro começou com a criação do mercado interno em meados de 1950

ambiente ou para a sociedade. Está enraizada nas características processuais das dimensões sociais, políticas, culturais, econômicas e ambientais de uma nação, desde que envolva a participação (SEN, 2000; SACHS, 2004; VEIGA, 2006; PENÃFIEL \& RADOMSKY, 2013). 
e se consolidou em 1960 com "o rompimento do complexo rural" após vivenciar simultaneamente o processo de industrialização, significando "o desenvolvimento da divisão do trabalho e constituição do mercado interno".

O segundo período que marca o processo de desenvolvimento rural no Brasil é analisado por Navarro (2001) a partir de meados de 1990, podendo ser compreendido pela percepção das 'impossibilidades do desenvolvimento'. Esta percepção considera que a modernização em si não conseguiu garantir os resultados propostos com sua disseminação, sendo necessário rediscutir suas dinâmicas, interesses e melhorias. Para tanto, é preciso caminhar por partes na análise do que foi o processo de modernização no Brasil.

A Revolução Verde foi um conjunto de estratégias adotadas para 'resolver' a condição alimentar da população mundial. Estas estratégias estavam centradas em algumas mudanças no sistema produtivo do campo: modificação das sementes por meio da genética; mecanização da produção; introdução de novas tecnologias no plantio, irrigação e colheita dos alimentos; uso intensivo de fertilizantes e pesticidas na produção; e, especialização a produção.

Em contextos internacionais, a Revolução Verde diz respeito a medidas dispensadas na solução da fome no mundo, em especial em países da África. Estas medidas foram ancoradas em múltiplas pesquisas e experimentos diversos capazes de garantir a produtividade no campo e, consequentemente, o aumento da produção. A preocupação central era o fornecimento de alimentos com o menor custo para o atendimento ao maior número de pessoas possíveis. Nesta situação, as ações técnicas e mecânicas direcionadas no campo possibilitaram o aumento na produção de alimentos geneticamente modificados que resistissem às pragas, doenças e ao próprio clima, garantindo a rápida inserção nos mercados com preços mais acessíveis aos consumidores (COSTABEBER, 2000).

O progresso técnico na produção agroalimentar permitiu, pois, o aumento da concorrência e baixa nos preços dos alimentos. Em contrapartida, aqueles produtores, majoritariamente de baixa renda, que não conseguiram se adequar ao sistema produtivo sofisticado, foram forçados a deixar a produção, investir em trabalhos alternativos ou atender precariamente aos comércios locais.

Para George Martine (1990), as transformações na agricultura que tiveram seu ápice de modernização na segunda metade da década de 1980, beneficiaram apenas aqueles que defendiam e intensificaram a condição de uma agricultura empresarial no Brasil. Esta valorização estava centrada na promoção de concentração fundiária e obtenção de recursos capazes de proporcionar integração econômica agrícola em caráter industrial.

Para Lide Albergoni \& Victor Pelaez (2007), no artigo intitulado "Da Revolução Verde à agrobiotecnologia: ruptura ou continuidade de paradigmas", a questão colocada é se a oportunidade tecnológica tem caminhado para a redução no uso de insumos químicos no campo, com o incremento de fertilizantes e pesticidas, ou se tais oportunidades têm sido vistas como alternativas para a valorização de empresas do ramo químico, estimulando o aprimoramento de práticas produtivas cada vez mais prejudiciais às condições socioambientais.

A inovação tecnológica pode ser compreendida, portanto, a partir da análise conceitual neo-schumpeteriana de paradigma e trajetória tecnológica, como uma forma estratégica de dimensionar os elementos representativos da continuidade e da ruptura "dos modelos tecnoeconômicos de produção". Com a operacionalização de tais termos, a inovação tecnológica é vista, 
[...] como um processo de formulação e de solução dos problemas produtivos que se constitui e transforma-se tanto em função de uma dinâmica interna de aquisição do conhecimento quanto em função de uma dinâmica externa de acumulação de capital (ALBERGONI \& PELAEZ, 2007, p. 33-34).

Esta perspectiva é complementar para a compreensão do funcionamento das diversas empresas que passaram a atuar na produção de insumos químicos e equipamentos tecnológicos voltados para a produção agrícola no contexto da Revolução Verde. Observa-se assim, a mudança nas relações econômicas mundiais, já que os países tidos como periféricos passaram a integrar as redes globais de exportação e importação de produtos relacionados à agricultura, como aconteceu, por exemplo, com o Brasil a partir da década de 1980.

Tanto os Estados Unidos quanto a Europa se destacaram no aumento da produção agrícola por meio dos investimentos massivos no campo. Foram adotadas diferentes estratégias para garantir a industrialização e mecanização da produção. Com a inserção dos países subdesenvolvidos na prática de produção agrícola em caráter industrial (GRAZIANO DA SILVA, 1982), as diferenciações entre nações, em termos produtivos, bem como as desigualdades entre os produtores na esfera local passaram a ser mais evidentes.

A modernização da agricultura propiciada pela Revolução Verde, favoreceu a desigualdade de renda e de propriedade nos espaços rurais. No Brasil, em muitas regiões não houve distribuição adequada de terra, mas sim, o favorecimento de produtores rurais ricos no controle de terras e capital, sobressaindo sobre os produtores mais pobres e menos engajados na situação agrícola do país. Em contrapartida, os produtores mais engajados se beneficiaram na distribuição de terras, por meio de redes de relações sociais centradas principalmente em favores. As consequências da Revolução Verde podem ser verificadas também, nos problemas ambientais evidenciados na poluição por agrotóxicos, erosão dos solos e perda da biodiversidade (COSTABEBER, 2000).

Percebe-se, portanto, que a modernização, contudo, não conseguiu resolver todos os problemas da agropecuária no país, ainda há grande concentração de terras nas mãos de poucos, degradação ambiental, ineficiência no uso dos solos e da água. As transformações nas estruturas sociais agrárias podem ser vistas pelo prisma da rearticulação nas relações rural-urbano e capitalização dos processos de trabalho rural, bem como da mercantilização da produção agrícola (GOODMAN et al., 1985; GRAZIANO DA SILVA, 1999; CAPORAL \& COSTABEBER, 2000; ALTIERI, 2008; EMBRAPA, 2018).

Mueller \& Martine (1997, p. 85), ao analisarem a modernização agropecuária no Brasil na década de 1980, compreendem que as transformações nas estruturas agrárias dos países em desenvolvimento assumiram caráter heterogêneo, definidos por eles de "estilos de desenvolvimento da sociedade". Para eles, as configurações assumidas pelas estruturas sociais agrárias nos anos após 1980, são resultado das condições sociopolíticas do contexto de sua recorrência. A concentração de terra nas mãos de poucos se deu a partir da ausência de políticas adequadas por parte do Estado, favorecendo assim que determinados grupos sociais no campo se sobressaíssem em relação.

Entre as diversas consequências desse processo de transformação experimentado pela agricultura brasileira podem-se destacar os altos índices de migração do campo, observados no fenômeno do êxodo rural tão conhecido no país. Mais de 30 milhões de pessoas deixaram o campo em busca de melhores condições de vida nas cidades entre 1960 e 1970, reconfigurando as relações sociais nestes 
espaços. A liberação de mão de obra do campo chamou a atenção dos estudiosos das questões agrárias, que passaram a dedicar-se na análise das ocupações dessas empresas, bem como nas implicações desse processo para a agricultura do país (MUELLER \& MARTINE, 1997; ABRAMOVAY, 1999).

Para Singer (1985), ao analisar o papel da urbanização no processo de desenvolvimento capitalista, tendo a cidade de São Paulo como referência, percebe-se que os movimentos migratórios observados nas saídas das populações do campo em direção às cidades remetem a dois aspectos distintos. Por um lado, diz respeito à estagnação no campo, em que as atividades se tornam obsoletas devido a não readequação aos avanços da modernização. A expulsão neste caso, é representada pelo não interesse ou ausência de condições econômicas que permitam a sobrevivência de determinado indivíduo no campo. Por outro lado, a cidade passa a representar tudo o que há de mais avançado em termos de modernização, se configurando, portanto, em atração para as populações em busca de oportunidades trabalhistas e de melhor qualidade de vida. A cidade torna-se atrativa para a mão de obra com possibilidade de engajamento em diversas atividades a serem desenvolvidas nos diferentes polos industriais.

Após a década de 1980, tem-se uma produção agrícola no Brasil bastante desigual, em que poucas regiões apresentam importantes avanços na adoção de técnicas e modernização produtiva, enquanto muitas outras são retratos do atraso, da pouca produção e produtividade, e cenários da ausência dos incentivos governamentais. Estas disparidades produtivas no Brasil lançam importantes desafios, em termos de produção e comercialização, para os pequenos produtores que buscam acessar o mercado.

Se analisarmos o setor de grãos (arroz, feijão, soja, milho e trigo) no Brasil, por exemplo, pode-se perceber a representação clara da análise feita no parágrafo anterior. Ao interpretar os índices de produtividade na produção de grãos entre 1975 e 2017 percebe-se um grande aumento, passando de 38 milhões de toneladas em 1975 para 236 milhões de toneladas em 2017, enquanto a área de plantio passou dos 38 milhões de hectares para 60 milhões de hectares. É possível observar, portanto, que houve aumento na produção e na produtividade, porém a concentração de terras dobrou neste período de 42 anos (EMBRAPA, 2018).

Os reflexos do desenvolvimento para a agricultura foram inúmeros e atingiram numerosos países pelo mundo. O desenvolvimento rural nestes contextos, possuía como finalidade principal a erradicação da fome no mundo por meio da produção de alimentos em larga escala, bem como a inserção econômica dos países nos mercados de exportação de alimentos.

No Brasil não foi diferente, o objetivo do ponto de vista da política agrícola neste caso era o impulsionamento da agricultura, a fim de aumentar a produtividade e garantir o crescimento da economia (ABRAMOVAY, 1999; REDIN \& FIALHO, 2010).

A transformação agrícola diz respeito, portanto, às formas tradicionais de dominação social no campo, com destaque para os conflitos em torno da terra e à atuação do poder público, no sentido de estimular as discrepâncias sociais e socioprodutivas, estimulando também, a política de modernização da agricultura. A modernização da agricultura resultou, portanto, em alterações na noção de rural no Brasil, bem como na compreensão das relações sociais estabelecidas neste espaço.

Ao avançar nas análises das mudanças no trabalho rural no Brasil (1992 - 2002), Kageyama (2001; 2004) percebe que no desenrolar do processo de modernização da agricultura, o campo tinha como função o fornecimento de mão de obra para as cidades. 
Com o decorrer das transformações agrárias, o espaço rural passa a reter, mesmo que uma parcela mínima, a população a partir de uma compreensão múltipla das funcionalidades do rural, indicando nesse sentido, seu caráter tanto de pluriatividade quanto de multifuncionalidade.

Como resultado, a própria categoria 'agricultor' sofre modificações em seu entendimento, a depender da escala de produção desenvolvida na unidade. $\mathrm{O}$ agricultor familiar é aquele que, embora seja detentor dos meios de produção (a terra e os equipamentos agrícolas), assume os trabalhos na unidade de produção, majoritariamente em pequeno espaço de terra, produzindo em pequenas escalas e sem o auxílio de grandes equipamentos ou maquinários.

Já o agricultor empresário apresenta um perfil oposto ao agricultor familiar. É aquele que produz em média ou grande porção de terra, é dono dos meios de produção e conta ainda com mão de obra assalariada para a execução do trabalho em sua unidade de produção. Seus resultados, portanto, são em grande escala e voltados para os mercados de commodities.

\section{CRÍTICAS À MODERNIZAÇÃO DA AGRICULTURA}

A Revolução Verde pode ser caracterizada como um conjunto de iniciativas tecnológicas adotadas por diferentes países a partir na década de 1950, incentivados por meio de políticas públicas nacionais, extensão rural e pesquisa agrícola. $\mathrm{O}$ crédito agrícola subsidiado pode ser considerado o instrumento que possibilitou a dissipação desse padrão de agricultura. A meta desse conjunto de inovações, portanto,

era o aumento da produção e da produtividade das atividades agrícolas, assentando-se para isso no uso intensivo de insumos químicos, das variedades geneticamente melhoradas de alto rendimento, da irrigação e da motomecanização (ALMEIDA, 1997, p. 7).

O desenvolvimento sustentável surge, portanto, como um conjunto de práticas capazes de oferecer à relação consumo e natureza, o equilíbrio necessário para que se possa alcançar o abastecimento em massa e de forma consciente (LUZZI, 2007).

Para Penãfiel \& Radomsky (2013, p. 156), é justamente quando muitos dos países do mundo demonstravam crescimento econômico sem precedentes que o tema do meio ambiente emergiu de forma particular.

$\mathrm{O}$ ambientalismo se tornou, portanto, uma forma crítica de pensamento sobre a vida moderna ao agregar no mesmo patamar as dimensões sociais, política, ambiental e econômica. Tal pensamento orientou alertas globais sobre a sustentabilidade ambiental, tendo a Conferência das Nações Unidas sobre o Meio Ambiente ocorrida em 1972 em Estocolmo, Suécia, como um marco ao levantar a problemática ambiental enquanto interesse de âmbito mundial.

O resultado dessa conferência não atingiu o esperado pelos analistas desse acontecimento, já que os diagnósticos apresentados no evento não se concretizaram. Porém, marcaram importantes avanços na percepção do horizonte humano ao possibilitar o crescimento populacional e a diminuição nos riscos de guerra nuclear entre os países em função dos processos de desenvolvimento buscados por estas nações.

Em outras palavras, a noção de desenvolvimento sustentável surge como oposição às práticas insustentáveis presentes nas inadequações econômicas, ambientais e sociais adotadas pelos países em seu desenvolvimento contemporâneo.

Esta noção nasce da compreensão da finitude dos recursos naturais e das injustiças sociais provocadas pelo modelo de desenvolvimento vigente na maioria dos países (ALMEIDA, 1997, p. 19).

Nesta perspectiva, 
a noção de desenvolvimento sustentável vem sendo utilizada como portadora de um novo projeto para a sociedade, capaz de garantir, no presente e no futuro, a sobrevivência dos grupos sociais e da natureza (ALMEIDA, 1997, p. 20).

Tal percepção se difundiu rapidamente pelo mundo como uma categoria-chave na solução da relação entre a problemática ambiental e o consumo humano. Contudo, conforme orienta o autor, um alerta sobre as especificidades dessa noção se faz necessário, a fim de estabelecer melhores compreensões sobre os significados, conceitos e ideias que norteiam esta prática. É preciso dimensionar claramente os limites e alcances dessa noção, bem como suas implicações paras as diferentes esferas da sociedade e da natureza.

Para Penãfiel \& Radomsky (2013, p. 162) o Relatório de Brundtland é falho ao se amparar na visão utilitarista do processo de desenvolvimento, jogando para segundo plano a dimensão social. Portanto, é necessário agregar também, tanto a participação quanto os valores da humanidade na problemática ambiental, pois, " [...] ver os seres humanos em termos de necessidades é uma redução absurda do que seja a humanidade".

Com uma compreensão mais completa sobre o desenvolvimento sustentável, Adriana Penãfiel e Guilherme Radomsky compreendem que ele pode ser definido,

[...] como um processo de expansão das liberdades das pessoas, de modo que isso não comprometa as liberdades das gerações futuras, combinando solidariedade com a geração atual e com as futuras, de modo que se compatibilizem viabilidade econômica, superação da pobreza e da desigualdade, preservação da biodiversidade, limitação de uso de recursos não renováveis e governança democrática (PENÃFIEL \& RADOMSKY, 2013, p. 160).

A noção de desenvolvimento sustentável, sem parecer exaustivo, abriga diferentes percepções alternativas para a reprodução das sociedades, centrando-se dessa forma, em produções socialmente justas, economicamente viáveis, economicamente sustentáveis e culturalmente aceito, "recuperando técnicas, valores e tradições" (ALMEIDA, 1997, p. 22). Contudo, os limites e desafios de sua concepção ao ser transposto para a realidade empírica precisam ser meticulosamente analisados.

Nestas condições, a transição agroecológica é marcada pela passagem da perspectiva produtivista para os ideais de ecologização. Neste processo, as questões ecológicas se chocam com as condições sociais e propiciam um espaço fecundo para a reflexão sobre as dinâmicas produtivas em contextos de insegurança alimentar, levando-se em consideração suas relações com a natureza e a população. Esta transição, ou mesmo "crise do produtivismo", representa o surgimento de novos estilos de agricultura centrados nos usos mais equilibrados dos recursos naturais disponíveis no ambiente (COSTABEBER, 2000, p. 17).

\section{A Agricultura de baSE}

\section{AGROECOLÓGICA E A CONSTRUÇÃO DE POLÍTICAS PÚBLICAS}

A agroecologia enquanto uma abordagem capaz de orientar as dinâmicas produtivas em contextos locais, surge como um caminho transformador associado à agricultura e aos desafios colocados pelo abastecimento populacional com alimentos de qualidade. A agroecologia alinha-se à sustentabilidade enquanto estratégia produtiva, buscando respostas concretas para as lacunas existentes sobre as formas adequadas e eficientes de produção em contextos marcados pela insegurança alimentar.

A vertente agroecológica busca integrar em sua análise as dimensões da agricultura e ecologia, aprofundando nos componentes que envolvam os 
aspectos socioeconômicos, socioculturais e tecnológicos dos sistemas agrícolas. Com esta medida, torna-se possível para os produtores, a transformação da produção tradicional para práticas mais adequadas ao consumo humano com respeito aos recursos providos pela natureza (SANTOS \& CHALUBMARTINS, 2012).

A aproximação entre a produção e o consumo passa a ser a estratégia mais recorrente no comércio agroecológico local, buscando a valorização justa das diferentes dimensões que compõem este quadro de relações, sejam elas culturais, econômicas, sociais ou políticas (SANTOS \& CHALUB-MARTINS, 2012).

A abordagem agroecológica permite aos pesquisadores, a utilização de ferramentas analíticas capazes de auxiliar na captação de conhecimentos e técnicas dos agricultures, ao "desenvolver agrossistemas com uma dependência mínima de insumos agroquímicos e energéticos externos" à unidade produtiva (ALTIERI, 2008, p. 23). A agroecologia é nesse sentido, uma alternativa transformadora dos sistemas produtivos que buscam integrar as dimensões sociais da humanidade aos recursos naturais.

Produzir sustentavelmente, portanto, remete à capacidade de articulação de diferentes estratégias na busca pelo equilíbrio dos sistemas agrícolas. $\mathrm{O}$ agroecossistema está, nesse sentido, nas potencialidades desenvolvidas nos sistemas produtivos, que favoreçam a diversificação e adaptação de cultivos alimentares. É preciso, pois, considerar métodos alternativos nos usos do solo como recursos de sobrevivência, buscando tanto a ampliação quanto a preservação da biodiversidade dos ecossistemas (COSTABEBER, 2000; LUZZI, 2007; ALTIERI, 2008).

A organização social que se orienta em torno das produções agroecológicas, assume a centralidade na execução de papéis em prol de um desenvolvimento sustentável comum. A agroecologia pode ser compreendida ainda, como alternativa no estímulo às interações entre a sociedade e a natureza, ao fornecer

[..] as ferramentas metodológicas necessárias para que a participação da comunidade venha a se tornar a força geradora dos objetivos e atividades dos projetos de desenvolvimento (ALTIERI, 2008, p. 27).

As manifestações e denúncias sobre as produções agrícolas prejudiciais à saúde humana apresentaram-se com considerável incidência a partir dos anos 1980 por meio de encontros, conferências e congressos sobre a temática da sustentabilidade. A contaminação por agrotóxicos no Brasil passou a ser agenda de pesquisa para diversos autores que se debruçavam nas problemáticas ambiental e agrícola do contexto, se caracterizando como abordagens radicais e mesmo hostis nas análises do processo de modernização agrícola. Com muitos empecilhos, os movimentos ecológicos se firmaram em 1978 como um grupo de agricultura alternativa com discussões bastante proeminentes na promoção de uma agricultura saudável e de qualidade para a relação humano-natureza (LUZZI, 2007).

Conforme sinaliza Luzzi (2007), os defensores da agricultura alternativa criticavam exatamente aquela lacuna observada por Almeida (1998) sobre o desenvolvimento sustentável, ao elencar que a ciência e o poder público concebiam a pesquisa de forma reducionista e linear, sem considerar a dimensão social como um todo. Portanto, é possível observar os choques entre as percepções do desenvolvimento sustentável, ainda frágil do ponto de vista conceitual, com os avanços de uma agricultura ecológica baseada na qualidade alimentar e produções mais conscientes. A gestão democrática da diversidade se torna mais uma vez, a chave de acesso para a construção de categorias mais completas que consigam apresentar soluções para a problemática ambiental. 
A produção agrícola de base familiar vem apresentando-se nos últimos anos como alternativa viável na promoção de alimentos de qualidade para o combate à alimentação de baixa qualidade, tão recorrente no mundo. A problemática alimentar está centrada mais na qualidade do alimento, com intensa utilização de conservantes e transgênicos, do que em sua escassez propriamente dito, bastando analisar os altos índices de obesidade, colesterol, hipertensão, dentre outros. A mudança nos padrões de consumo alimentar tornou-se interesse de saúde pública em níveis globais. O que importa, portanto, não é a quantidade produtiva da agricultura desenvolvida pelo viés familiar ou não, mas sim, o tipo de alimento produzido, sua qualidade e os aspectos sobre como estes alimentos são produzidos, distribuídos e quem consome (NIEDERLE \& MARQUES, 2016).

É nesse aspecto que se inserem a produção e comercialização em mercados locais da agricultura ecológica.

Para os adeptos da produção ecológica, o principal diferencial da agricultura familiar se encontra em seu potencial para articular formas alternativas de 'fazer agricultura' que [...] promovem a segurança alimentar e nutricional (NIEDERLE \& MARQUES, 2016, p. 276).

Em contextos marcados pela problemática da saúde pública, conforme salientado no parágrafo anterior, estas experiências passam a ser compreendidas como caminhos promissores na busca pela qualidade alimentar da sociedade em contextos locais, servindo de reflexos para outras realidades.

Com produções distanciadas 16 anos, tanto Costabeber (2000) quanto Niederle \& Marques (2016) concordam que a 'fragilidade' encontrada na produção agroecológica e que tem sido a oportunidade para críticas de percepções opostas à estas práticas, são as dificuldades em suprir as necessidades alimentares mundiais com produções em pequenas escalas. A maior problemática neste processo pode ser sintetizada na valorização da industrialização da agricultura, em oposição às práticas mais sustentáveis, sinalizando o seu potencial na solução da fome no mundo.

As práticas agroecológicas ocupam o nicho de mercado que busca unir a produção consciente ao consumo de alimentos de qualidade. Portanto, a produção alternativa tem assumido destaque no cenário produtivo da agricultura brasileira e ganhando cada vez mais os diferentes mercados, ao apresentar "[...] tentativas de reconexão e relocalização das práticas de produção e consumo alimentar" (NIEDERLE \& MARQUES, 2016, p. 279).

É nesta perspectiva que se inserem os interesses públicos, ainda que tímidos, sobre as formas alternativas de obtenção de alimentos de qualidade. Como consequência, a institucionalização das agriculturas ecológicas como caminhos qualificados e estruturados para o atendimento dos interesses 'políticos' de abastecimento, tem sido o foco de complexas redes de atores sociais interessado na situação. Com a Política Nacional de Agroecologia e Produção Orgânica, este tipo de produção se estrutura em bases mais sólidas, contando com a formatação de regras e normas para a produção (NIEDERLE, 2013; 2014; 2015; BUSTAMANTE \& DIAS, 2014; NIEDERLE \& MARQUES, 2016).

Conforme destacam Niederle et al. (2019), as políticas públicas para a agroecologia no Brasil assumiram patamares de destaque no cenário global dos últimos anos. Este sucesso é compreendido como resultado das articulações entre os diferentes atores sociais que englobam a produção de base ecológica. A participação dos movimentos sociais, sindicais e colaboradores tem chamado a atenção para práticas mais sustentáveis na produção agroalimentar. Tais atuações têm viabilizado experiencias positivas para a agricultura familiar brasileira, contribuindo para o seu caráter sustentável. 
Conforme destacam ao analisarem as gerações de políticas públicas para agricultura familiar e as formas de interação entre Estado e sociedade no Brasil, Grisa \& Schneider (2014) percebem que as novas relações entre Estado e sociedade civil por meio da participação social, contribuíram para que emergissem novos atores políticos que passaram a ser reconhecidos como sujeitos de direitos - a agricultura familiar. Tal processo veio atrelado à necessidade de regras e compreensões que modificaram os aspectos socioeconômicos das populações, com destaque para a população rural.

As gerações de políticas públicas para o setor agrícola brasileiro podem ser dimensionadas, portanto, em três casos. A primeira geração diz respeito ao surgimento de políticas públicas voltadas para o setor agrário do Brasil, necessitando em meados da década de 1950 recorrer a estratégias governamentais para o processo de industrialização da atividade agrícola, como alternativa em oposição às importações. A segunda geração se pautou nos processos sociais e assistenciais às configurações da agricultura, com dedicação especial à agricultura de base familiar, estimulando a diminuição da desigualdade econômica entre os produtores rurais. A terceira geração de políticas públicas, por fim, dedicando-se às problemáticas alimentar e ambiental com perspectivas mundiais, elaborou um conjunto de medidas de estímulo à produção agrícola e construção de mercados voltados, principalmente, à sustentabilidade e a promoção de alimentos saudáveis em combate a insegurança alimentar e nutricional (GRISA \& SCHNEIDER, 2014).

É necessário destacar a importância do Programa Nacional de Fortalecimento da Agricultura Familiar - Pronaf, institucionalizado na década de 1990, como âncora nas políticas públicas para a agricultura familiar. Ao consolidar-se, o Programa contribuiu ao longo de sua história para a promoção da agricultura familiar, bem como mais adiante, para a inclusão da juventude rural, ao possibilitar a transformação da estrutura agrária e garantir melhores condições de vida à população local.

De forma suscinta, portanto, o Pronaf trata-se, portanto, de

[...] uma estrutura voltada para o financiamento, com taxas de juros $\mathrm{e}$ condições diferenciadas de pagamento, para operações de crédito de custeio e investimento desenvolvidas no âmbito da agricultura familiar incluindo: custeio da safra e de atividades de processamento, investimento em máquinas agrícolas e equipamentos, infraestrutura de produção e serviços agropecuários, entre outras linhas de atuação (NIEDERLE et al. 2019, p. 278).

Para a existência de tais contribuições foram necessárias diferentes articulações sociais em prol da produção agrícola de base familiar. As diferentes demandas dos movimentos sociais ocasionaram em importantes inovações no Pronaf, destacando a sua ramificação em atendimento às especificidades da agricultura familiar (Pronaf Mulher, Pronaf Jovem, dentre outros). Tais inovações subsidiaram avanços nas unidades produtivas, bem como garantiram em seu tempo, a transformação social, por meio da perspectiva socioassistencial (NIEDERLE et al. 2019), da condição de vida de diferentes produtores, que saíram da situação de extrema pobreza e integram-se em mercados qualificados da agricultura familiar.

O problema, contudo, conforme observado por Niederle et al. (2013, p. 279), é que o Pronaf não atingiu o alcance esperado. Além do número reduzido de produtores que conseguiram acessar esta política, diversos aspectos relativos à sua estrutura dificultaram melhores resultados. Os produtores mais pobres, que representavam a maioria no contexto de surgimento do Pronaf, não conseguiram acessar o crédito, que de modo geral atendia às "commodities tradicionais". Ainda segundo os autores, como respostas às desigualdades nesta política pública, as articulações de 
diferentes movimentos sociais e sindicais buscaram meios de denunciar as deficiências do Programa e a sua não adequação às diferentes realidades da agricultura familiar brasileira.

Para a produção agroecológica, o Pronaf apresentou iniciativas peculiares depois de muitos anos sem essa perspectiva de assistência a este tipo de agricultura. Essas iniciativas ganharam corpo no segundo governo de Lula, com destaque para as ramificações do Pronaf voltadas à promoção de produções agrícolas de base orgânica e agroecológica.

Ao avançar nas análises das políticas públicas para a agricultura brasileira, ainda que sutilmente, percebe-se que por meio do decreto $\mathrm{n}^{\mathrm{o}} 7.794$, de 20 de agosto de 2012 assinado pela então presidente do Brasil Dilma Rousselff, fica instituída a Política Nacional de Agroecologia e Produção Orgânica PNAPO. O objetivo desta ação na esfera pública foi construir subsídios para estimular práticas sustentáveis na produção agrícola do país. Esta medida estava centrada ainda, em estabelecer o consumo de alimentos mais saudáveis à população, proporcionando políticas públicas mais adequadas a seu desenvolvimento.

No plano dessa Política Nacional, um parágrafo é dedicado à ampliação da participação da juventude rural na produção de alimentos agroecológicos e orgânicos. Há também, no parágrafo seguinte, a preocupação com a igualdade de gênero ao estimular iniciativas que visem minimizar as desigualdades entre os trabalhos de homens e de mulheres, por meio da autonomia econômica, ações e programas específicos.

No plano produtivo, a Política Nacional estabeleceu também, diretrizes e possibilidades para o desenvolvimento da agricultura de base agroecológica e orgânica no país. Foram garantidos incentivos, por meio do crédito rural, financiamento, seguro agrícola e de renda, compras governamentais, medidas fiscais e tributárias, dentre outros. Estas ações foram fundamentais para as transições alternativas na produção agrícola.

A dedicação desta política à promoção de pesquisa e inovação científica e tecnológica, assistência técnica e rural, extensão rural, formação profissional e educação, modificou a forma como a agroecologia era vista no Brasil. É considerável o número crescente de cursos técnicos e superiores criados nos últimos anos voltados para a produção agrícola de base ecológica. Considera-se importante, também, os avanços observados nas atuações da assistência técnica e extensão rural ao auxiliarem as transformações das agriculturas tradicionais em modelos sustentáveis de agriculturas agroecológicas.

$\mathrm{O}$ estímulo à produção agroecológica e orgânica no país por parte do governo, possibilitou a redução considerável da problemática alimentar no Brasil, ainda que importantes desafios precisem ser superados nessa transição. As compras governamentais da agricultura agroecológica e orgânica, por meio do Programa Nacional de Alimentação Escolar - PNAE e do Programa de Aquisição de Alimentos - PAA, possibilitaram o acesso a alimentos de qualidade a uma importante parcela da população, bem como estímulo às práticas da agricultura familiar alternativa e a minimização das desigualdades sociais e econômicas entre os produtores rurais nas mais diversas realidades produtivas.

De modo geral, a Política Nacional de Agroecologia e Produção Orgânica pode ser avaliada como um progresso considerável, resultado da articulação social de diferentes atores, na promoção de perspectivas mais adequadas para as produções agrícolas familiares centradas na prática agroecológica.

A partir dos delineamentos da PNAPO, o Plano Nacional de Agroecologia e Produção 
Orgânica (PLANAPO) previu, em sua primeira fase, um total de 125 ações e um investimento de $\mathrm{R} \$ 8,8$ bilhões em ações de promoção da agroecologia, subdivididas em quatro objetivos estratégicos: (a) produção, uso e conservação dos recursos naturais, (b) conhecimentos, (c) comercialização e (d) consumo (NIDERLE et al. 2019, p. 284).

Estas observações são importantes, sobretudo, para a análise dos lançamentos mais recentes do Censo Agropecuário de 2017. Este Censo destaca o aumento do número de estabelecimentos rurais que fazem uso de agrotóxicos, conforme pode ser observado na imagem adiante. Atrelado a este crescimento de 20,4\% nos últimos 11 anos, os dados evidenciaram ainda a elevação no número dos produtores rurais analfabetos que fazem uso dos agrotóxicos, sendo, portanto, 15,6\% dos produtores, destacando ainda que destes, $89 \%$ assumiram não ter recebido nenhum tipo de informação ou orientação técnica sobre os malefícios dos agrotóxicos.

Em relação aos estabelecimentos que declararam utilizar agrotóxicos, $73 \%$ tinham menos de 20 hectares de área de lavouras. A despesa desse tipo de estabelecimento com o produto é significativamente menor em comparação com o gasto das médias e grandes concentrações de terra. Dos 32 bilhões de reais da despesa com agrotóxicos, apenas $7,4 \%$ são de estabelecimentos desse porte. A despesa média, no valor de $\mathrm{R} \$ 1.918$ no período de referência, significou $\mathrm{R} \$ 160$ por mês (CENSO AGROPECUÁRIO, 2019, $\mathrm{s} / \mathrm{p})$.

Do ponto de vista crítico dos avanços nas políticas públicas para a agricultura brasileira, tais resultados acendem um alerta sobre a situação do produtor agrícola, bem como sobre os resultados e alcances das políticas e programas públicos direcionados para o campo.

Tais números evidenciam, ainda, a complexidade na produção agroalimentar brasileira e suas diversas dimensões (educação e orientação técnica). Produzir alimentos de qualidade requer a articulação dessas diferentes dimensões, conforme orientado pela Política Nacional de Agroecologia e Produção Orgânica. O aumento considerável nos números de pequenos estabelecimentos rurais que fizeram uso de agrotóxicos no sistema produtivo, bem como a ausência de orientações técnicas, evidencia as necessidades de experiências coletivas e participação social em torno da produção agrícola no Brasil.

A agroecologia sustenta desafios relativos a uma produção que considere as diferentes dimensões relacionadas à sua prática (social, econômico, político e ambiental), com também nos entraves apresentados pela competitividade dos processos da industrialização da agricultura. Estes desafios, do ponto de vista das políticas públicas, são percebidos como empecilhos para a promoção de práticas mais sustentáveis e que valorizem a saúde humana e a preservação ambiental.

A agricultura agroecológica carece, portanto, de análises mais criteriosas que levem em consideração seus aspectos estruturais e produtivos, agregando-se ao seu potencial qualitativo de abastecimento das populações por meio de produtos saudáveis na esfera local. Estes elementos aplicados à compreensão das configurações das experiências coletivas e estratégias adotadas pela produção agroecológica, podem sinalizar os caminhos mais adequados, ainda que provisórios nos contextos de transformação, na apresentação de soluções para as problemáticas ambiental e alimentar em níveis globais.

Importantes desafios se fazem presentes na promoção de práticas mais equilibradas e adequadas na produção agrícola. Conforme analisado nos parágrafos anteriores, os avanços observados nas políticas públicas são resultado de diferentes articulações sociais entre os atores ligados à agricultura. As articulações sociais se apresentam, portanto, como desafios, em termos de estrutura, para a promoção da agroecologia no Brasil. 
Em caráter de síntese, novas articulações sociais não seriam potenciais na busca por soluções para este cenário apresentado pelo Censo Agropecuário de 2017? A participação da juventude viabilizaria experiências coletivas positivas para a agricultura familiar com produção agroecológica? Quais explicações para os interesses, ou não, dos jovens rurais em produções agroecológicas? Como a juventude tem se mobilizado no acompanhamento de políticas públicas para a agroecologia? A autogestão dos empreendimentos agrícolas possibilita a maior participação social e política dos produtores? Estas são algumas inquietações que orientam esta proposta de pesquisa.

\section{ECONOMIA SOLIDÁRIA E AUTOGESTÃO DOS EMPREENDIMENTOS AGRÍCOLAS}

A economia solidária pode ser compreendida como o conjunto de atividades de cunho econômico, propriamente dito, centradas na cooperação e solidariedade entre os indivíduos. Trata-se de redes de apoio coletivo que visam construir relações mais extensas na promoção de comercializações justas, tanto para o consumidor quanto para o produtor em seu sistema econômico. Há, quando aplicado ao mundo rural, a valorização do ser humano e de seu trabalho por meio da autogestão dos empreendimentos, caracterizando-se ainda como um mecanismo de inclusão social e de desenvolvimento territorial.

Para Paul Singer (2001), a economia solidária se apresenta como uma alternativa em oposição à economia capitalista. A economia solidária, por meio de cooperativas ou associações, deve pautar-se na obtenção de lucro, mas diferentemente da economia capitalista, seu excedente deve ser convertido em solidariedade e promoção de condições trabalhistas para membros menos afortunados do grupo.
O ponto crucial que define a economia solidária é sua capacidade de solidariedade nos mercados. Enquanto na economia capitalista os aspectos competitivos são ressaltados como essenciais, na economia solidária a atenção ao desenvolvimento social e econômico do outros são fundamentais no conjunto de interesses de determinados grupos. Para esta perspectiva, o essencial é o desenvolvimento coletivo e não individual quando o assunto é a economia. É uma prática com possibilidade de concretização em realidades locais e contextos mais restritos, já que as relações proximais são mais presentes e fortes, bem com forte presença do capital social e humano desses grupos específicos (SINGER, 2002).

O que está em jogo na economia solidária não são as representações de ganhadores ou perdedores, já que esta ideia presume uma sociedade desigual, mas sim, a capacidade de crescimento econômico igualitário entre os diferentes atores envolvidos. Ainda em oposição à perspectiva capitalista de competição,

a solidariedade na economia só pode se realizar se ela for organizada igualitariamente pelos que se associam para produzir, comerciar, consumir ou poupar. A chave dessa proposta é a associação entre iguais em vez do contrato entre desiguais (SINGER, 2002, p. 9).

A perspectiva central para a economia solidária é que se a cooperativa ou associação progredir, todos lucram nesse processo. Caso aconteça o contrário, todos são responsáveis pelo desenvolvimento negativo e, portanto, devem arcar em conjunto com esta situação, formulando novas ordens de ação. A superação deve surgir na articulação dos diferentes indivíduos que compõem o cenário local dessa experiencia coletiva. A chave para esta condição neste sistema econômico peculiar é a superação da desigualdade (SINGER, 2001; 2002). 
A economia solidária no contexto brasileiro também foi resultado da articulação entre os diferentes sujeitos sociais na esfera política, como a própria perspectiva conceitual de definição do termo orienta. Tais movimentos traziam como bandeira de luta a geração de trabalho e renda pautados na solidariedade, inclusão social e promoção de perspectivas mais justas no desenvolvimento. A potencial participação social no desenvolvimento das ações enviesadas pela economia solidária, são essenciais neste processo.

Esta organização social surgiu a partir dos próprios interesses dos trabalhadores, cujas mobilizações se deram nas buscas por melhores aproveitamentos dos contextos de transformação do mundo do trabalho capitalista. Transformação esta, ancorada nas relações de competição nas diferentes estruturas de trabalho, desemprego, desigualdades sociais ou exploração. Estas condições negativas contribuíram para as articulações sociais centradas no estabelecimento de relações entre as oportunidades econômicas e as relações sociais entre os indivíduos de determinado grupo (SINGER, 2000; 2001; CARVALHO, 2011).

A economia solidária é baseada na autogestão de administração dos empreendimentos, com igualdades, em termos econômicos, entre os indivíduos. Enquanto a economia capitalista é estruturada por meio da hierarquia na administração, estabelecendo a desigualdade entre os trabalhadores, bem como especificando as atividades desenvolvidas, a fim de que os trabalhadores saibam apenas aquilo que é exigido em suas funções. Neste sistema de heterogestão, o nível funcional na empresa é que definirá o quanto sobre aquela estrutura o trabalhador deverá saber e se engajar. Na economia solidária, por sua vez, a administração é democrática e baseada na autogestão, em que as decisões são tomadas em assembleias ou reuniões com todos os trabalhadores (SINGER, 2001).
Neste último tipo de organização, a participação dos trabalhadores é essencial para as dinâmicas que visam resultados coletivos. Os interesses individuais devem ser deixados de lado, a não ser que se caracterizem em pautas comuns, a fim de que a solidariedade não seja ameaçada nem se perca o vínculo proximal entre os indivíduos. Portanto, o estímulo e a participação em conjunto são essenciais para que não seja desqualificado o vínculo participativo entre os membros de determinada unidade, bem como as novas conquistas e articulações sociais não deixem de ser alcançadas (SINGER, 2001).

No plano das atividades agrícolas, a economia solidária pode apresentar-se como uma alternativa viável na autogestão dos empreendimentos, possibilitando maior participação social, bem como a inserção em mercados diferenciados. Marcada pela concentração de renda, desigualdade social e exclusão social, os produtores que se dedicam à agricultura familiar têm procurado cada vez mais, alternativas de revalorização de suas atividades, associando-se a outras atividades econômicas ou experiências alternativas (SCHNEIDER, 1995). Poderia acrescentar também, que os produtores estão buscando novas formas sociais e organizativas de produção e cooperação na agricultura, a fim de superar as situações problemáticas desta condição. Torna-se, portanto, a economia solidária, importante mecanismo neste tipo de transição estrutural da produção.

A economia solidária, atrelada à agroecologia, tem sido o caminho alternativo para os produtores que procuram articulações coletivas em prol da sustentabilidade e melhor inserção nos mercados. É possível encontrar em diferentes partes do mundo, experiências coletivas que têm buscado não só na produção agroecológica, mas também na economia solidária, conciliações entre os aspectos econômicos da produção aos aspectos sociais que delimitam estas produções. 
No âmbito da produção agroecológica, a economia solidária tem solidificado como alternativa frente à sustentabilidade.

Ao longo da última década, diversos eventos contribuíram para evidenciar as complexas articulações existentes entre processos econômicos, ecológicos, políticos e sociais, não somente em nível global, mas em diferentes escalas territoriais (SCHMITT, 2010, p. 55).

A economia solidária afirma-se como alternativa frente à organização social de cunho econômico, a partir da década de 1980, buscando integrar práticas associativas que passaram a abarcar tanto o campo quanto a cidade. Contudo, só após a década de 1990 é que a economia solidária se configura em uma prática amplamente utilizada no Brasil em diferentes regiões e condições de produção.

Embora seja uma abordagem recorrentes em associações e cooperativas com perfis comuns espalhadas pelo Brasil, a análise dessa experiência deve ser desenvolvida à luz da realidade local e específica, a fim de compreender as reais conformações assumidas pelos indivíduos, à escolha desse conjunto de atividades econômicas que conta com a participação social como caráter essencial em seu processo.

Conforme apresentado no quadro a seguir e ressaltado anteriormente, é possível compreender a economia solidária como um recurso que conta com a articulação social de diferentes atores interessados em sua estrutura e alternativa de funcionamento baseado na cooperação. Estes princípios estruturam a economia solidária como uma 'nova' alternativa de associação entre indivíduos com ideais comuns.

\section{Princípios da economia solidária}

1. valorização do trabalho, do saber e da criatividade dos seres humanos;
2. reconhecimento do trabalho associado e da propriedade associativa dos meios de produção como elementos fundamentais na construção de formas renovadas de organização econômica;

3. autogestão;

4. construção de redes de colaboração solidária como estratégia de integração entre diferentes empreendimentos.

Fonte: Adaptado de Schmitt, 2010, p. 58.

Conforme destaca Schmitt (2010), os últimos dados disponíveis de 2007, apresentaram a economia solidária presente em torno de 21.763 empreendimentos pelo Brasil, entre espaço rural e urbano. Desse número total, $48 \%$ diz ocupar os espaços rurais como local de trabalho e reprodução das atividades, $17 \%$ declaram ocupar os espaços mistos, estando presentes tanto no campo como na cidade. De modo complementar, $35 \%$ declarou ocupar apenas o espaço urbano para as atividades cuja economia solidária se tornou central. A produção agrícola é central para estes empreendimentos, se diferenciando em várias opções de produtos e serviços cuja finalidade é a sustentação econômica das famílias.

Em relação ao faturamento mensal, cerca de $60 \%$ deles declararam faturar até $\mathrm{R} \$ 5$ mil por mês. Aproximadamente $72 \%$ dos empreendimentos afirmaram que, no ano anterior, os resultados da atividade econômica (sem contar as doações de recursos) haviam permitido ou pagar as despesas e ter uma sobra ou, simplesmente, pagar as despesas. Em 15\% dos casos os resultados econômicos obtidos não haviam possibilitado o pagamento das despesas. Em relação à remuneração mensal dos sócios do empreendimento, $49,7 \%$ dos grupos formais e informais entrevistados remuneravam seus sócios, $31 \%$ deles com remunerações de até um salário mínimo. Mais da metade dos empreendimentos (52\%) havia tido acesso a crédito nos últimos doze meses e $39 \%$ deles haviam realizado investimentos neste período (SCHMITT, 2010, p. 59). 
No que diz respeito à sustentabilidade, segundo os resultados apresentados pelo Atlas de Economia Solidária de 2007, boa parte dos estabelecimentos declararam fornecer produtos sem agrotóxicos, sendo portando, uma parcela expressiva de empreendimentos localizados na região Nordeste do Brasil. Como prática adicional visando a produção orgânica, 7.121 empreendimentos faziam o tratamento dos resíduos gerados e 634 praticavam o reaproveitamento de materiais (SCHMITT, 2010). Tais aspectos reafirmam as condições alternativas de produção e consumo de alimentos, bem como de reutilização de bens que seriam descartados e que podem ser utilizados na produção sustentável.

A economia solidária alinhada à agricultura familiar de base agroecológica tem apresentado importantes resultados no fornecimento de bens e serviços que prezam pela sustentabilidade. É nesse aspecto que a participação da juventude rural se evidencia como potencial aglutinador dessas percepções, procurando agregar diferentes experiências em prol de soluções mais adequadas para as problemáticas ambiental e alimentar.

\section{CONSIDERAÇÕES FINAIS}

O rural brasileiro, envolvendo sua organização social e estrutura, tem sinalizado para importantes mudanças nos últimos anos, sendo necessário compreendê-lo como 'novo', a partir das especificidades apresentadas em cada realidade local. Este encaminhamento é justificável enquanto análise, já que são múltiplas as condições inerentes ao perfil organizacional da agricultura familiar nos contextos mais atuais. Estas mudanças partem das transformações orientadas pela modernização na agricultura brasileira, conforme foi abordado nos tópicos anteriores.
Este novo rural pode ser caracterizado, portanto, a partir de pelo menos duas transformações essenciais que resultaram do processo de modernização agrícola: a divisão do trabalho e a combinação de atividades agrícolas com outras atividades externas, sejam agrícolas ou não - a então, situação pluriativa do produtor que exerce mais de uma atividade econômica. Tais situações contribuem para o surgimento de percepções que questionam a delimitação familiar deste tipo heterogêneo de agricultura.

Vale ressaltar que a noção de agricultura familiar, contudo, é frágil do ponto de vista analítico e de sua utilização. Não existe na realidade brasileira consenso sobre quais categorias de agricultores se encaixariam nessa definição, sejam elas referentes a campesinato ou pequena produção, por exemplo. Construir conceitualmente a agricultura familiar, torna-se, portanto, uma tarefa problemática, já que as bases sólidas de ponto de partida nessa compreensão residem apenas no amplo entendimento sobre o caráter familiar desse tipo de produção. São necessárias reflexões que levem em consideração, além da diversidade social, as condições econômicas e produtivas da agricultura familiar na realidade local (ABRAMOVAY, et al., 1998; SPANEVELLO, 2008; SCHNEIDER, 2009; SANTOS, 2017).

Sobre o processo de modernização da agricultura no caso brasileiro, destaca-se que com o aumento da produção e a busca pela alta produtividade, como visto nos tópicos anteriores, houve o crescimento da necessidade de pesticidas e insumos químicos de modo geral capazes de atender a produção em larga escala. Na década de 1960 a indústria de agrotóxicos atingiu seu ápice no fornecimento de ativos capazes de garantir a demanda produtiva do setor agrícola, porém, sem apresentar resultados satisfatórios sobre seus possíveis danos às populações e ao ambiente. Após este período, surgiram 
questionamentos pontuais sobre esta produção, abalando a situação desse setor industrial. Como consequência, abriu-se espaços para a competição com alternativas de produtos diferenciados que pudessem agregar maior qualidade ao alimento, que minimizassem os danos ambientais e ainda garantissem que fossem acessíveis ao maior número de pessoas nos mercados.

É nesse contexto de problemas ambientais e sociais que surgem as discussões sobre o desenvolvimento sustentável, sendo impulsionado como resposta "ao declínio na qualidade da vida rural, bem como à degradação da base de recursos naturais associada à agricultura moderna". Nesse sentido, a produção agrícola, a partir das transformações e implicações socioeconômicas e naturais de seu desenvolvimento, deixa de ser uma questão puramente técnica e passa a incorporar um processo condicionado, dimensionado e definido por dimensões sociais, culturais, políticas e econômicas (ALTIERI, 2008).

A desigualdade social em termos de renda entre os produtores rurais, se manifesta como resultado da inserção produtiva de trabalhadores rurais com melhores condições econômicas e auxiliados pelos incentivos governamentais, em oposição aos produtores que dispunham de poucos recursos (mão de obra, terra e capital). A modernização da agricultura no Brasil modifica não só os aspectos produtivos (aumento da produção e melhorias nas técnicas e equipamentos), mas também as relações sociais entre os produtores no campo e a própria compreensão de espaço rural.

A participação social no desenvolvimento da agricultura agroecológica, configura-se em estratégia de integração em torno do sistema produtivo e na garantia de uma agricultura oposta ao tipo apresentado pela agricultura predatória de larga escala. São levados em consideração na produção agroecológica, os saberes e práticas dos indivíduos envolvidos no processo, visando a sociodiversidade na produção e comercialização. A agricultura de base agroecológica não pode ser analisada como um modelo a ser imposto aos produtores, mas sim, como uma meta baseada em diferentes estilos que estabelece como parâmetro a promoção de qualidades em seu desenvolvimento. Não é uma prática que deve ser executa levando em consideração apenas os potenciais econômicos viabilizados, mas sim, as oportunidades de integração social e promoção da sustentabilidade (COSTABEBER, 2000).

A agroecologia representa as práticas produtivas na agricultura opostas ao crescimento econômico experimentado na transformação agrária no contexto da Revolução Verde. Associada ao desenvolvimento sustentável, a agroecologia afirmase como um modo alternativo de organização econômica que busca desenvolver práticas conscientes na utilização dos recursos da natureza e promoção de alimentos saudáveis.

Para a Nilza Luzzi (2007), a noção de agroecologia enquanto uma produção agrícola alternativa começou a ser estrutura nos debates da década de 1980, embora as articulações sociais contra o sistema moderno produtivo tenham começado em anos anteriores. Tal noção afirmou-se como oposição aos processos de modernização da agricultura no Brasil que buscava quantidade sem consideração da qualidade dos alimentos. As críticas aos impactos da agricultura moderna subsidiaram elementos para a estruturação de padrões mais eficientes qualitativamente na produção de alimentos sem agrotóxicos. Conforme será destacado adiante, as implicações dessas condições produtivas são diversas, sobretudo, para a esfera social em termos de organização civil politicamente orientada.

No início de sua articulação, conforme destaca Luzzi (2007), o movimento ecológico não tinha 
claramente definido a concepção de produção agrícola no perfil discutido, abrindo espaços para constantes críticas e controvérsias em torno de sua atuação. A exigência era pela concretização das ideias apresentadas pelo movimento, que até então encontrava-se no plano da articulação e da atuação sociopolítica. Contudo, com o amadurecimento das trocas de experiências e aprofundamento nas perspectivas teóricas, o movimento firmou-se e estabeleceu diretrizes para a definição do que seria uma produção ecológica, bem como seus benefícios para as sociedades e a natureza. Em pouco tempo, esta categoria ganhou adeptos por todo o Brasil e passou a estabelecer vínculos em redes internacionais de apoio à causa, que ao se identificarem contrariamente às produções que utilizam agrotóxicos, propõem articulações em massa visando a redução desse sistema produtivo.

Em termos de considerações finais, considerase, portanto, que a modernização no campo contribuiu para a (re)definição dos processos agroalimentares, sendo base para o crescimento de críticas sobre a qualidade da produção agrícola, sua quantidade e as implicações negativas dispensadas para o meio ambiente. As transições agrícolas observadas na agroecologia, por exemplo, reforçam a importância da promoção dessas críticas no sistema agroalimentar, bem como da necessidade de autogestão como alternativa para essa transição produtiva de forma justa entre os produtores e consumidores nos mercados agroalimentares.

\section{REFERÊNCIAS BIBLIOGRÁFICAS}

ABRAMOVAY, R. (coord.) ... [et al.]. Juventude e agricultura familiar: desafios dos novos padrões sucessórios. Brasília, Unesco, 1998.

ABRAMOVAY, R. Agricultura familiar e desenvolvimento territorial. Reforma Agrária Revista da Associação Brasileira de Reforma
Agrária, v. 28 nº. 1,23 e 29, nº 1, jan./dez., 1998 e jan./ago., 1999.

ALBERGONI, L; PELAEZ, V. Da Revolução Verde à agrobiotecnologia: ruptura ou continuidade de paradigmas? Editora da UFPR: Revista de Economia, v. 33, n. 1 (ano 31), p. 31-53, jan./jun. 2007.

ALMEIDA, J. Por um novo sentido à prática da agricultura. In: Agroecologia: a dinâmica produtiva da agricultura sustentável. 5. ed. Porto Alegre: Editora da UFRGS, 1997.

ALTIERI, M. Agroecologia: a dinâmica produtiva da agricultura sustentável. 5. ed. Porto Alegre: Editora da UFRGS, 2008.

BUSTAMANTE, P.; DIAS, T. Segurança Alimentar e Agrobiodiversidade. Reforma Agrária, v. 01, 2014.

CAPORAL, F. R.; COSTABEBER, J. A. Agroecologia e Desenvolvimento Rural Sustentável: perspectivas para uma nova extensão rural. Revista Agroecologia e Desenvolvimento Rural Sustentável, v. 1, n. 1, jan./mar. 2000. p. 01-166.

CARVALHO, Keila. Economia solidária como estratégia de desenvolvimento: uma análise crítica a partir das contribuições de Paul Singer e José Ricardo Tauile, 2011. Disponível em: http://www.ipea.gov.br/code2011/chamada2011/pdf/a rea2/area2-artigo21.pdf. Acesso em: 17 de novembro de 2015 .

COSTABEBER, J. A. Transição agroecológica: do produtivismo à ecologização. In: Agroecologia e Desenvolvimento Rural Sustentável: perspectivas para uma nova extensão rural. Revista Agroecologia e Desenvolvimento Rural Sustentável, v. 1, n. 1, jan./mar. 2000. p. 17-48.

EMBRAPA. Visão 2030: o futuro da agricultura brasileira. Brasília, DF: Embrapa, 2018.

GOODMAN, E. D.; SORJ, B.; WILKINSON, J. Agroindústria, políticas públicas e estruturas sociais rurais: análises recentes sobre a agricultura brasileira. Revista de Economia Política, v. 5, nº , out./dez. 1985.

GRAZIANO DA SILVA, J. A modernização dolorosa: estrutura agrária, fronteira agrícola e trabalhadores rurais no Brasil. Rio de Janeiro: Zahar, 1982.

Do complexo rural aos complexos agroindustriais. In: ___ A nova dinâmica da agricultura brasileira. Campinas: UNICAMP /IE, p.1-40, 1996. 
Tecnologia e agricultura Familiar. Porto Alegre: Editora da UFRGS, 1999.

GRISA, C.; SCHENEIDER, S. Três gerações de Políticas Públicas para a agricultura familiar e formas de interação entre sociedade e Estado no Brasil. RESR, Piracicaba-SP, v. 52, p. 125-146, 2014.

KAGEYAMA, A. As múltiplas fontes de renda das famílias agrícolas brasileiras. São Paulo: Agricultura em São Paulo, v. 48, nº. 2, p. 57-69, 2001.

. Mudanças no trabalho rural no Brasil, (1992 - 2002). São Paulo: Agricultura em São Paulo, v. 51, $\mathrm{n}^{\circ} .2$, p. 71-84, jul./dez., 2004.

LUZZI, N. O debate agroecológico no Brasil: uma construção a partir de diferentes atores sociais. Tese (Doutorado em Ciências Sociais em Desenvolvimento, Agricultura e Sociedade), Universidade Federal Rural do Rio de Janeiro, UFRRJ, 2007.

MARTINE, G. A trajetória da modernização agrícola: a quem beneficia? In: Fases e Faces da Modernização Agrícola. Revista de Planejamento e Políticas Públicas, nº. 3, Brasília: IPEA, 1990.

MENDONÇA, S. R. D. Sociedade civil, sociedade política e agricultura no Brasil (1910 - 1945). Uberlândia: História e Perspectivas, v. 48, p. 43-80, jan./jun., 2013.

MUELLER, C. C.; MARTINE, G. Modernização da agropecuária, emprego agrícola e êxodo rural no Brasil - a década de 1980. Revista de Economia Política, v. 17, nº 3 (67), jul./set. 1997.

NAVARRO, Z. Desenvolvimento rural no Brasil: os limites do passado e os caminhos do futuro. Estudos Avançados, v. 15, nº. 43, p. 83-100, 2001.

NIEDERLE, P. A.; ALMEIDA, L. A nova arquitetura dos mercados para produtos orgânicos: o debate da convencionalização. In: NIEDERLE, P. A.; ALMEIDA, L.; VEZZANI, F. M. (Org.). Agroecologia: práticas, mercados e políticas para uma nova agricultura. Curitiba: Kayrós, UFPR, p. 23-67, 2013.

NIEDERLE, P. A. Os agricultores ecologistas nos mercados para produtos orgânicos: contramovimentos e estratégias de relocalização dos circuitos alimentares. Sustentabilidade em Debate, v. 5, n. 3, p. 79-96, set./dez., 2014.

A agrobiodiversidade como recurso estratégico nos novos mercados agroalimentares. In: SANTILLI, J.; BUSTAMANTE, P.; BARBIERI, R.
Agrobiodiversidade e agroecologia. Brasília: Embrapa-ANA, 2015.

NIEDERLE, P. A.; MARQUES, F. C. Produção ecológica de alimentos e mudanças institucionais: implicações para a construção de novos mercados. In: MARQUES, F. C.; CONTERATO, M. A.; SCHENEIDER, S. (Orgs.). Construção de Mercados e Agricultura Familiar: desafios para o desenvolvimento rural. Porto Alegre, Editora da UFRGS, 2016.

NIEDERLE, P. A.; SABOURIN, E.; SCHMITT, C. J.; ÁVILA, M. L. D.; PETERSEN, P.; ASSIS, W. S. D. A trajetória brasileira de construção de políticas públicas para a agroecologia. Redes (Santa Cruz do Sul. Online), v. 24, n. 1, p. 270-291, jan./abr., 2019.

PENÃFIEL, A.; RADOMSKY, G. Desenvolvimento e sustentabilidade. Curitiba: InterSaberes (Série Administração e Negócios), 2013.

REDIN, E.; FIALHO, M. A. V. Política agrícola brasileira: uma análise histórica da inserção da agricultura familiar. Campo Grande, Anais... $48^{\circ}$ Congresso da Sociedade Brasileira de Economia, Administração e Sociologia Rural, 25 a 28 de julho de 2009.

SACHS, I. Desenvolvimento: includente, sustentável, sustentado. Rio de Janeiro: Garamond, 2004.

SANTOS, A. S. Dos. Um olhar sobre as juventudes rurais: desafios, possibilidades e limitações no município de Porteirinha (MG). Ambiente e Território, Universidade Federal de Minas Gerais, Universidade Estadual de Montes Claros / Instituto de Ciências Agrárias, Montes Claros, 2017.

SANTOS, F. P. D.; CHALUB-MATINS, L. Agroecologia, consumo sustentável e aprendizado coletivo no Brasil. Educação e Pesquisa, São Paulo, v. $38, n^{\circ} .2$, p. 469-483, abr./jun. 2012.

SCHMITT, C. J. Economia solidária e agroecologia: convergências e desafios na construção de modos de vida sustentáveis. Mercado de Trabalho, v. 42, p. 5564, 2010.

SCHNEIDER, S. As transformações recentes da agricultura familiar no Rio Grande do Sul: o caso da agricultura em tempo parcial. Ensaios FEE, Porto Alegre, v. 16, no. 1, p. 105-129, 1995.

SEN, A. K. Desenvolvimento como liberdade. São Paulo: Companhia das Letras, 2000.

SINGER, P. Economia política da urbanização. Brasília: Editora Brasiliense, ed. 10, 1985. 
Economia solidária versus economia capitalista. Sociedade e Estado, Brasília, v. 16, n. 12, jun./dez., 2001.

Introdução à economia solidária. São Paulo: Editora Fundação Perseu Abramo, 2002.

SPANEVELLO, Rosani Marisa. A dinâmica sucessória na agricultura familiar. Tese de Doutorado. Porto Alegre: Programa de PósGraduação em Desenvolvimento Rural, Universidade Federal do Rio Grande do Sul, 2008.
VEIGA, J. E da. Desenvolvimento sustentável: o desafio para o século XXI. 2. ed. Rio de Janeiro: Garamond, 2006.

WELCH, C. A. Vargas e a reorganização da vida rural no Brasil (1930 - 1945). Trad. Venceslau Alves de Souza. São Paulo: Revista Brasileira de História, v. 36, no. 71, p. 81-105, 2016. 